\title{
A Case of Severe Diabetic Ketoacidosis Associated with Pembrolizumab Therapy in a Patient with Metastatic Melanoma
}

This article was published in the following Dove Press journal:

Diabetes, Metabolic Syndrome and Obesity: Targets and Therapy

\section{Lili Wu}

Bixun Li

Department of Integrated Medicine, Guangxi Medical University Cancer Hospital, Nanning, Guangxi, 53002I, People's Republic of China
Correspondence: Bixun Li Department of Integrated Medicine, Guangxi Medical University Cancer Hospital, Nanning, Guangxi, 53002I, People's Republic of China Email 260228096@qq.com

\begin{abstract}
Pembrolizumab, a monoclonal antibody against programmed cell death-1 receptor, was licensed for advanced cancers. Although the use of pembrolizumab can enhance the effect of cancer treatment, it can increase immune-related adverse events. We describe an elderly woman who developed ketoacidosis after receiving pembrolizumab to treat metastatic melanoma. In the presentation, laboratory analysis showed that hyperglycemia and anion gap metabolic acidosis was consistent with diabetic ketoacidosis. Except for pembrolizumab, no other predisposing factors were found. The blood glucose levels before using pembrolizumab were normal. The patient responded well to intravenous fluids, insulin therapy, and treatment to correct electrolyte disturbances. She was diagnosed with severe diabetic ketoacidosis (DKA) because of new-onset diabetes mellitus which associated with pembrolizumab therapy. Two months after she was discharged from the hospital, she continued to take insulin as well as metformin to treat her diabetes. Clinicians need to be alert about diabetes mellitus and ketoacidosis for patients undergoing pembrolizumab treatment.
\end{abstract}

Keywords: DKA, diabetic ketoacidosis, pembrolizumab, metastatic melanoma

\section{Background}

Pembrolizumab is an IgG4 monoclonal antibody which binds to the programmed cell death 1 (PD-1) receptors on the T-cells activates the immune system to attack the tumor cells. So far, more than 2250 trials have explored monoclonal antibodies against PD-1 and its ligand programmed death-ligand 1 (PD-L1). ${ }^{1}$ Pembrolizumab was licensed for use in the treatment of advanced melanoma, metastatic head and neck squamous cell cancers, advanced non-small-cell lung cancer, certain types of gastroesophageal cancer, and lymphoma.

As body normal cells expressing PD-L1 are also affected by the immune checkpoint inhibition (ICI) medication, these drugs are associated with multiple immune-related adverse events (irAE) especially related to the endocrine system.

The range of unfortunate endocrine side-effects during immune checkpoint inhibition (ICI) includes thyroid function disorders, hypophysitis, and immune checkpoint inhibitor-induced type 1 diabetes mellitus (CPI-T1DM). CPI-T1DM is determined as a severe insulin deficiency clinical manifestation of ketoacidosis and low or absence of C-peptide level. ${ }^{2}$

Pembrolizumab-induced diabetes is rare, a small number of cases initially presented with life-threatening diabetic ketoacidosis if not diagnosed timely and 
handled properly. Here we describe a serious case of severe DKA associated with pembrolizumab therapy in a young woman patient with metastatic melanoma.

\section{Case Presentation}

A 38-year-old female patient with no previous history of diabetes or other autoimmune disease was admitted with a history of nausea and vomiting for 1-day and polyuria and polydipsia for half a month. Although she was drinking plenty of water to maintain a subjective feeling of dehydration, the symptoms were still progressing.

In March 2015, she was diagnosed with malignant melanoma of the mole on the left thigh region and along with the mass in the right groin (pT4a). The patient was treated with wide local excision and lymph node clearance of the right groin.

In June 2017, she was found to have right thigh skin metastases and had a repeat excision. She developed in pulmonary metastases and commenced pembrolizumab at a dose of $2 \mathrm{mg} / \mathrm{kg}$ every three weeks from March 2018. She received night cycles of pembrolizumab; the most recent dose was taken one week before the current acute attack. During treatment, she developed no obvious immunotherapy-related adverse effects. Notably, the patient did not participate in the clinical trial. She had no personal or family history of DM, pancreatitis, or other autoimmune diseases.

On examination, she was conscious and oriented but was clinically dehydrated. She was not afebrile and normotensive but looked unwell. Vital signs showed that heart rate was around at $105 / \mathrm{min}$, blood pressure was 103 / $71 \mathrm{mmHg}$, respiratory rate was $28 / \mathrm{min}$ with oxygen saturations of $99 \%$ on ambient air, Her BMI was $22 \mathrm{~kg} / \mathrm{m}^{2}$. She had no remarkable abnormality on physical examination.

\section{Investigation}

Laboratory analyses (Table 1) showed severe hyperglycemia (serum glucose was $32.98 \mathrm{mmol} / \mathrm{L}$ ) and strong positive urine ketones. The primary metabolic acidosis was confirmed by the results of arterial blood gas which showed that with partial respiratory compensation $(\mathrm{pH}: 7.15$, HCO3: 9.4, $\mathrm{PaCO}_{2}$ : 17).

Her glycosylated hemoglobin (HbA1c) at admission was increased at $9.71 \%$. There had been rapid development of ketoacidosis that no obvious hyponatremia and hyperkalemia. Additional examinations of the patient showed that the potential possibility of acute pancreatitis, glucagon tumor, somatostatinoma, or severe infectious process was unrevealing.
An OGTT test was done and showed that low C-peptide level during $3 \mathrm{~h}$ test (oh: $0.04 \mathrm{ng} / \mathrm{mL}, 1 \mathrm{~h}$ : $0.05 \mathrm{ng} / \mathrm{mL}, 2 \mathrm{~h}: 0.06 \mathrm{ng} / \mathrm{mL}, 3 \mathrm{~h}: 0.07 \mathrm{ng} / \mathrm{mL}$ ) with concomitant blood glucose (oh: $14.48 \mathrm{mmol} / \mathrm{L}, 1 \mathrm{~h}: 22.95 \mathrm{mmol} /$ L, $2 \mathrm{~h}: 25.16 \mathrm{mmol} / \mathrm{L}, 3 \mathrm{~h}: 24.18 \mathrm{mmol} / \mathrm{L})$.

Further laboratory evaluation revealed serum for glutamic acid decarboxylase (GAD) antibody, insulin autoantibody, and islet cell antibody were negative.

\section{Treatment}

Based on the patient's medical history, symptoms, signs, examination results, and drug-using of pembrolizumab, she was diagnosed with severe DKA because of newonset diabetes mellitus which associated with pembrolizumab therapy. According to DKA's diagnosis and treatment guidelines, she was treated with plenty of saline intravenous hydration, insulin drip, and management of electrolytes to lower the blood glucose and correct acidosis. Subsequently, with the resolution of hyperglycemia and acidemia, all these metabolic disorders were corrected. Upon resolution of her DKA, she continued to require insulin therapy in addition to metformin given.

\section{Outcome and Follow-Up}

Two months after she was discharged from the hospital, she continued to take insulin as well as metformin to treat her diabetes. In view of her excellent response to the treatment of advanced melanoma with pembrolizumab, she decided to continue treatment with this medication for another 6 months. To date, her diabetes is controlled very well with insulin and metformin treatment.

\section{Discussion}

There has recently been rapid development in the use of therapeutic antibodies to activate the immune system to treat cancers. Tumor cells attempt to evade the human immune system by activating the inhibitory pathways that inhibit a tumor-specific $\mathrm{T}$ cell response. Among these inhibitory pathways, the PD-1-PD-L1 pathway is the most important one. ${ }^{3}$ The study found that more and more types of tumors express PD-L1 on the cell surface to escape the human immune response. Based on this tumor cell evasion mechanism, anti-PD-1 and anti-PD-L1 checkpoint inhibitors have been developed to achieve anti-tumor effects through the immune pathway. These anti-PD-1 and anti-PD-L1 checkpoint inhibitors block the PD-1 pathway, restoring $\mathrm{T}$ cell function and immune response to antitumor. ${ }^{4}$ Pembrolizumab is a kind of IgG4 recombinant 
Table I Laboratory Data at Patient Admission

\begin{tabular}{|c|c|c|}
\hline Variables & Result & $\begin{array}{c}\text { Reference Range } \\
\text { (Adult) }\end{array}$ \\
\hline Serumglucose (mmol/L) & 32.98 & $3.86-6.11$ \\
\hline Magnesium (mg/dL) & 0.76 & $0.6-1.2$ \\
\hline Calcium & 2.02 & $2.0-2.5$ \\
\hline Troponin I (ng/mL) & 0.57 & $0-1.68$ \\
\hline Hemoglobin AIC (\%) & 9.71 & $4.8-6.1$ \\
\hline C-peptide (ng/mL) & $0.78-5.19$ & 0.07 \\
\hline \multicolumn{3}{|l|}{ Blood gases } \\
\hline Arterial blood gas $\mathrm{pH}$ & 7.15 & $7.35-7.45$ \\
\hline $\mathrm{PaCO} 2$ (mmHg) & 17 & $35-45$ \\
\hline $\mathrm{PaO} 2$ (mmHg) & 117 & $83-108$ \\
\hline $\mathrm{HCO}^{-}(\mathrm{mmol} / \mathrm{L})$ & 14 & $22-28$ \\
\hline Lactate (mmol/L) & I.I & $0.5-1.6$ \\
\hline \multicolumn{3}{|l|}{ Urine analysis } \\
\hline Specific gravity & 1.025 & $1.010-1.025$ \\
\hline $\mathrm{pH}$ & 6 & $5.5-7.0$ \\
\hline Protein $(\mathrm{mg} / \mathrm{dL})$ & - & - \\
\hline Glucose (g/dL) & ++++ & - \\
\hline Bilirubin & - & - \\
\hline Urobilinogen & - & - \\
\hline Erythrocyte (cell/hpf) & - & - \\
\hline White cell (cell/hpf) & - & - \\
\hline Ketones & +++ & - \\
\hline \multicolumn{3}{|c|}{ Type I diabetes-related antibodies } \\
\hline $\begin{array}{l}\text { Glutamic acid decarboxylase } \\
\text { antibody }(\mathrm{IU} / \mathrm{mL})\end{array}$ & - & - \\
\hline Islet cell antibody (IU/mL) & - & - \\
\hline $\begin{array}{l}\text { Insulinoma-associated antigen } \\
(\mathrm{IU} / \mathrm{mL})\end{array}$ & - & - \\
\hline
\end{tabular}

antibody, which lies in the PD-1 receptor on T-cells, and reorganizes its interaction with PD-L1, so that the T cells destroy the cells expressing PD-L1.

Anti-PD-1 drugs may active self-reactive T cells, leading to an autoimmune response against pancreatic islet cells. ${ }^{5}$ In addition, recent evidence in human indicates that the expression of PD-1 in CD4(+) T cells of type 1 diabetes mellitus patients was significantly lower than of healthy control subjects. This may reveal that the low expression of PD-1 in CD4(+) T cells may be involve in the occurrence of type 1 diabetes through $\mathrm{T}$ cell activation. $^{6}$

T1DM is a chronic autoimmune disease. It is characterized by the permanent destruction of the insulinsecreting $\beta$ cells resulting in insufficient insulin secretion. $^{7}$ Since the acquisition of T1DM is an autoimmune disease, we believe that pembrolizumab is related to the development of T1DM in our patient due to its unique role and the relationship with irAEs. DKA is a common acute and severe complication of diabetes mellitus (DM), and patients are often accompanied by severe electrolyte and metabolic disorders. The patient's condition in the emergency room is serious, and the medical team who needs to take care of it immediately deal with this emergency according to the management guidelines. ${ }^{8}$ Even though the patient's GAD, IAA, and ICA antibodies were all negative, the low C-peptide level and the appearance of sudden and persistent hyperglycemia with DKA all confirmed insulin-dependent $\mathrm{DM}$, consistent with the reported cases and reviews. ${ }^{9,10}$

Before using of pembrolizumab, the normal levels of repeatedly fasting blood glucose indicating that the patient had no diabetes before the use of pembrolizumab. The HbAlc of this patient was significantly increased at the time of admission, hyperglycemia, diabetes and glycation of hemoglobin were considered after the use of pembrolizumab suggests that pembrolizumab closely related to the occurrence of diabetes. In conclusion, this confirms the causal relationship between pembrolizumab and the appearance of DKA in our patient with new-onset DM.

There are relatively few cases have been reported of pembrolizumab-induced DKA, but DKA is generally considered to be a severe immune-endocrinal side effect of checkpoint blockade and is more commonly associated with PD-1 and PD L1 inhibitors like nivolumab or pembrolizumab. In addition, the reported cases of primary adrenal insufficiency and T1DM were less, 0.7 and $0.2 \%$ respectively. ${ }^{11}$ It seems that T1DM is more related to PD-1 and PD-L1 blockade (or combination immunotherapy) than to ipilimumab alone. ${ }^{12}$ This is important and leads to consideration that regular monitoring of chemistries in metastatic melanoma patients before using the immunotherapy pembrolizumab as well as other malignant tumor. ${ }^{13}$

As a complication of anti-PD-1 antibody therapy, our current knowledge of DKA is based on case reports and small case series. Most of these patients appear in autoimmune diabetes induced by immunotherapy. ${ }^{14}$ DKA usually presents the sum of several doses of immunity, which is not common for single dose $\mathrm{e}^{14}$.

The PD-1 pathway plays an important role in the adjustment of autoimmune diabetes. ${ }^{15}$ PD-1 blockade can lead to type 1 diabetes in mouse models of all ages, ${ }^{16}$ and its mechanisms can involve both humeral and cellular autoimmunity. ${ }^{17}$ 
It has been reported that pembrolizumab-induced diabetes is rare, it may occur in $0.4 \%$ of patients. ${ }^{18}$ DKA is needed as a rare but important side effect of anti-PD-1 inhibitors. It is important for clinicians to recognize this side effect, and patients should receive education regarding signs and symptoms to monitor for the development of diabetes or diabetic ketoacidosis. Regular monitoring of glucose levels and hemoglobin A1C levels maybe beneficial. Further research is needed to identify patient risk factors that may predispose patients to the development of this complication.

In conclusion, although our case only reported the relationship between ICI treatment and the development of DKA, the association between immunotherapy and its potential side effects should be concerned considering the increasing number of indications for anti-tumor therapy and the longer duration of immunotherapy. DKA is lifethreatening and doctors are advised to be on high alert for patients undergoing ICI treatment.

\section{Patient Consent}

All procedures performed in this report involving human participants were in accordance with the ethical standards of the institutional and/or national research committee and with the 1964 Helsinki declaration and its later amendments or comparable ethical standards. Written informed consent has been provided by the patient to have the case details and any accompanying images published. It was approved by Guangxi Medical University Cancer Hospital Humanities Clinical and Research Center Ethics Committee for the publication of the case report.

\section{Acknowledgments}

This work was supported by grants from the National Natural Science Foundation of China (Grant Numbers: 81660138 and 81860146); Project of Guangxi Food and Drug Administration (Grant Numbers:201808-5);National Key Research \& Development Plan for Precision Medicine Key Program (2016YFC0901200; 2016YFC0901205); Guangxi Autonomous region administration of traditional Chinese medicine self-Financing project (Grant Numbers: GZZC2019136); and Guangxi Medical and Health SelfFinancing Project (Grant Numbers:Z20180636).

\section{Author Contributions}

L.W. and B.L. substantially contributed to the conception and design, L.W. contributed to the acquisition and analysis of the data. All authors made a significant contribution to the work reported, whether that is in the conception, study design, execution, acquisition of data, analysis and interpretation, or in all these areas; took part in drafting, revising or critically reviewing the article; gave final approval of the version to be published; have agreed on the journal to which the article has been submitted; and agree to be accountable for all aspects of the work.

\section{Disclosure}

The authors report they have no conflicts of interest related to this work.

\section{References}

1. Tang J, Yu JX, Hubbard-Lucey VM, Neftelinov ST, Hodge JP, Lin Y. Trial watch: the clinical trial landscape for PD1/PDL1 immune checkpoint inhibitors. Nat Rev Drug Discov. 2018;17(12):854-855. doi: $10.1038 / \mathrm{nrd} .2018 .210$

2. Quandt Z, Young A, Anderson M. Immune checkpoint inhibitor diabetes mellitus: a novel form of autoimmune diabetes. Clin Exp Immunol. 2020;200(2):131-140. doi:10.1111/cei.13424

3. Du L, Herbst RS, Morgensztern D. Immunotherapy in lung cancer. Hematol Oncol Clin North Am. 2017;31(1):131-141. doi:10.1016/j. hoc.2016.08.004

4. Ribas A. Releasing the brakes on cancer immunotherapy. $N$ Engl $J$ Med. 2015;373(16):1490-1492. doi:10.1056/NEJMp1510079

5. Okamoto M, Okamoto M, Gotoh K, et al. Fulminant type 1 diabetes mellitus with anti-programmed cell death-1 therapy. J Diabetes Investig. 2016;7(6):915-918. doi:10.1111/jdi.12531

6. Fujisawa R, Haseda F, Tsutsumi C, et al. Low programmed cell death-1 (PD-1) expression in peripheral CD4(+) T cells in Japanese patients with autoimmune type 1 diabetes. Clin Exp Immunol. 2015;180(3):452-457. doi:10.1111/cei.12603

7. Atkinson MA, Eisenbarth GS, Michels AW. Type 1 diabetes. Lancet. 2014;383(9911):69-82. doi:10.1016/S0140-6736(13)60591-7

8. American Diabetes A. 14. Diabetes care in the hospital: standards of medical care in diabetes-2018. Diabetes Care. 2018;41(Suppl 1): S144-S151. doi:10.2337/dc18-S014

9. Hakami OA, Ioana J, Ahmad S, Tun TK, Sreenan S, McDermott JH. A case of pembrolizumab-induced severe DKA and hypothyroidism in a patient with metastatic melanoma. Endocrinol Diabetes Metab Case Rep. 2019;2019. doi:10.1530/EDM-18-0153

10. Clotman K, Janssens K, Specenier P, Weets I, De Block CEM. Programmed cell death-1 inhibitor-induced Type 1 diabetes mellitus. J Clin Endocrinol Metab. 2018;103(9):3144-3154. doi:10.1210/jc.2018-00728

11. Barroso-Sousa R, Barry WT, Garrido-Castro AC, et al. Incidence of endocrine dysfunction following the use of different immune checkpoint inhibitor regimens: a systematic review and meta-analysis. JAMA Oncol. 2018;4(2):173-182. doi:10.1001/jamaoncol.2017.3064

12. Mellati M, Eaton KD, Brooks-Worrell BM, et al. Anti-PD-1 and Anti-PDL-1 monoclonal antibodies causing type 1 diabetes. Diabetes Care. 2015;38(9):e137-e138. doi:10.2337/dc15-0889

13. Kichloo A, Albosta MS, McMahon S, et al. Pembrolizumab-induced diabetes mellitus presenting as diabetic ketoacidosis in a patient with metastatic colonic adenocarcinoma. J Investig Med High Impact Case Rep. 2020;8:2324709620951339.

14. Gauci ML, Laly P, Vidal-Trecan T, et al. Autoimmune diabetes induced by PD-1 inhibitor-retrospective analysis and pathogenesis: a case report and literature review. Cancer Immunol Immunother. 2017;66(11):1399-1410. doi:10.1007/s00262-017-2033-8 
15. Ansari MJ, Salama AD, Chitnis T, et al. The programmed death-1 (PD-1) pathway regulates autoimmune diabetes in nonobese diabetic (NOD) mice. $J$ Exp Med. 2003;198(1):63-69. doi:10.1084/ jem. 20022125

16. Guleria I, GubbelsBupp M, Dada S, et al. Mechanisms of PDL1-mediated regulation of autoimmune diabetes. Clin Immunol. 2007;125(1):16-25. doi:10.1016/j.clim.2007.05.013
17. Hughes J, Vudattu N, Sznol M, et al. Precipitation of autoimmune diabetes with anti-PD-1 immunotherapy. Diabetes Care. 2015;38(4): e55-e57. doi:10.2337/dc14-2349

18. de Filette J, Andreescu CE, Cools F, Bravenboer B, Velkeniers B. A systematic review and meta-analysis of endocrine-related adverse events associated with immune checkpoint inhibitors. Horm Metab Res. 2019;51(3):145-156.

Diabetes, Metabolic Syndrome and Obesity: Targets and Therapy

\section{Publish your work in this journal}

Diabetes, Metabolic Syndrome and Obesity: Targets and Therapy is an international, peer-reviewed open-access journal committed to the rapid publication of the latest laboratory and clinical findings in the fields of diabetes, metabolic syndrome and obesity research. Original research, review, case reports, hypothesis formation, expert opinion and commentaries are all considered for publication. The manuscript management system is completely online and includes a very quick and fair peer-review system, which is all easy to use. Visit http://www.dovepress.com/testimonials.php to read real quotes from published authors. 